\title{
Differences in effectiveness of membrane fixation using periosteal vertical mattress and simple sling suture techniques in infrabony pocket treatment
}

\author{
Beta Widya Oktiani*, Sri Pramestri Lastianny** ${ }^{*}$, Ahmad Syaify** \\ *Department of Peridontics, Faculty of Dentistry, Universitas Lambungmangkurat, South Kalimantan, Indonesia \\ Periodontics Specialty Program, Faculty of Dentistry, Universitas Gadjah Mada, Yogyakarta, Indonesia \\ **Department of Periodontics, Faculty of Dentistry, Universitas Gadjah Mada, Yogyakarta, Indonesia \\ **JI Denta No 1 Sekip Utara, Yogyakarta, Indonesia; $₫$ correspondence: sri.pramestri@ugm.ac.id
}

Submitted: 24 ${ }^{\text {th }}$ July 2018; Revised: 26 $^{\text {th }}$ November 2018; Accepted: $12^{\text {nd }}$ March 2019

\begin{abstract}
Guide tissue regeneration (GTR) is the treatment of infrabony pockets for soft and hard tissue regeneration. Membrane is used as a barrier and prevents apical migration of the cells in epithelial tissues. Membrane fixation is one of the procedures in GTR treatment because resorbed membrane is less stable. Simple sling suture technique for membrane fixation has 1 anchorage, located in coronal flap, while periosteal vertical mattress suture technique has 2 anchorages in periosteum, making it more stable. This study aimed to study the differences in the effectiveness of membrane fixation using periosteal vertical mattress suture and simple sling suture techniques in terms of probing depth, relative attachment loss, and alveolar bone height in the treatment of infrabony pockets. The samples were divided into 2 groups. The first group was open flap debridement (OFD) with demineralized freeze dried bone allograft (DFDBA) application and membrane fixation with simple sling suture, while the second group was OFD with DFDBA application and membrane fixation with periosteal vertical mattress suture, observed on day $0,30^{\text {th }}$ day, and $90^{\text {th }}$ day. The results of the study showed significant differences in the probing depth and relative attachment loss (except from the $30^{\text {th }}$ day to the $90^{\text {th }}$ day), and there were no significant differences in the alveolar bone height from the baseline to the $90^{\text {th }}$ day, between the group of membrane fixation using simple sling suture and that of periosteal vertical mattress suture techniques on flap surgery. This study concluded that membrane fixation in the treatment of infrabony pocket with periosteal vertical mattress suture technique is more effective in reducing the probing depth and relative attachment loss, but there is no difference in increasing the alveolar bone height when compared to simple sling suture technique.
\end{abstract}

Keywords: alveolar bone height; infrabony pocket; membrane fixation of simple sling suture; membrane fixation of periosteal vertical mattress suture; relative attachment loss

\section{INTRODUCTION}

Periodontitis is periodontal tissue inflammation characterized by apical migration of junctional epithelium, attachment loss and alveolar crest. ${ }^{1}$ Prolonged periodontitis is usually diagnosed as chronic periodontitis. This may lead to the formation of a periodontal pocket, pathological tooth migration, shaking teeth, even tooth loss. ${ }^{2}$ One of the classifications of periodontal pocket is infrabony pocket, i.e. bone damage that occurs on the supporting tissues in which the bottom is apical or below the alveolar crest. ${ }^{1,3}$

Infrabony pocket requires more complex treatment. $^{3}$ There are a number of treatments, one of which is guide tissue regeneration (GTR) technique, i.e. periodontal treatment using membrane as barrier to prevent apical migration of cells in the epithelial tissues. The membrane used can be either resorbed or not resorbed. ${ }^{4}$

Experts have currently combined GTR with bone graft material to treat areas with bone damage or bone defects to yield more satisfactory results. ${ }^{5}$ These days, allograft materials have been commonly used as bone graft materials, i.e. bone graft materials derived from another individual with the same species. Allograft which is often used in periodontal therapy is DFDBA, i.e. bone graft material decalcified in hydrochloric acid then freeze-dried. ${ }^{5,6}$ 
Membrane stabilization or fixation is one of the procedures in bone and tissue regeneration. ${ }^{7}$ The use of resorbed membrane has several disadvantages, including less stable so it is less able to keep bone graft material in place, leading to a failure in the formation of bone matrix, thus membrane fixation is required in order to yield more satisfactory regeneration results. ${ }^{4}$

There are several ways of membrane fixation, one of which is simple sling suture, i.e. the type of suture that is usually used for flap repositioning. The advantages of this technique are more accurate repositioning, less trauma, quicker process, and simpler than other techniques. The disadvantages of this membrane fixation technique are this technique only has one anchorage which reduces the stabilization due to limited fixation, there is suture thread around the neck of the tooth which increases bacterial plaque accumulation and causes tooth infection. ${ }^{8}$ Another membrane fixation technique that currently is increasingly more popular is periosteal vertical mattress suture. ${ }^{4}$ This suture technique is one that involves periosteal region, apical region and palatal or lingual region. The advantage of this technique is a reduced risk of bone graft material migration to other area because it is limited by membrane fixation in both mesial and distal (two anchorages) parts inside the flap so the resulted bone and tissue regeneration is quite good. The disadvantages of this technique are greater wound trauma and a risk of tissue infection due to bacterial retention. ${ }^{8}$

The severity of periodontal diseases is determined by the result of examination of periodontal tissue conditions. The examination includes gingival tissue examination, measurement of probing depth (PD), measurement of clinical attachment loss (CAL), and radiographic examination to display the image of alveolar bone height. $^{1}$

\section{MATERIALS AND METHODS}

This was a quasi-experimental research. The samples of this study were 20 infrabony periodontal pockets in subjects suffering from chronic periodontitis. The subjects of the study were divided into 2 treatment groups. The first group was given OFD with DFBDA and membrane fixation using simple sling suture technique, while the second group was treated with OFD with DFBDA and membrane fixation using periosteal vertical mattress suture technique. The probing depth and relative attachment of the two groups were measured on day 0 before treatment, on the $30^{\text {th }}$ day, and the $90^{\text {th }}$ day after treatment. The examination of alveolar bone was performed on day 0 before treatment and on day 90 after treatment.

The procedures of periodontal flap surgery started used local anesthesia, injected after the surgery area was first sterilized using disinfectant. Vertical and sulcular full thickness flap incisions were performed. The flap was elevated and debridement was performed in bone defect by scaling root planning and curettage. Seventy five $\mathrm{mg} / \mathrm{mL}$ tetracycline $\mathrm{HCl}$ solution was applied to the hard tissue using sterile cotton pellets for 3 minutes which was replaced every 30 seconds, and rinsed using distilled water. Allograft bone graft material was applied DFDBA was placed on clean bone defect, resorbed pericardium membrane was added then membrane fixation was performed.

The membrane fixation for the first group was done using simple sling suture while that for the second group was performed using periosteal vertical mattress suture technique. Simple sling suture technique was done with a suture needle entering the membrane distally towards the palatal/ lingual part, encircling the neck of the tooth, then exiting buccally. The suture needle then entered mesially towards the palatal/lingual part, encircling around the neck of the tooth, then exiting buccally once again, then tied (Figure 1). Periosteal vertical mattress suture technique was performed by suturing the periosteum. The periosteum was obtained by split thickness incision in the apical/side part from the bone damage with a size of 2-4 $\mathrm{mm}$. The suture needle entered the periosteum towards the vertical/lingual flap vertically, then the mattress entered the periosteum buccally and tied (Figure 2).

The flap was returned and sutured with an interupted technique, and covered with periodontal pack (Coe-Pack). Patients were given antibiotics, 


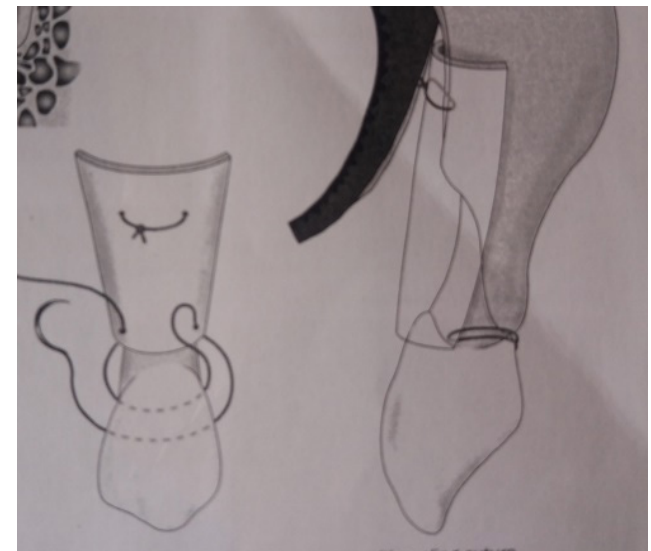

Figure 1. Membrane fixation with simple sling suture ${ }^{9}$

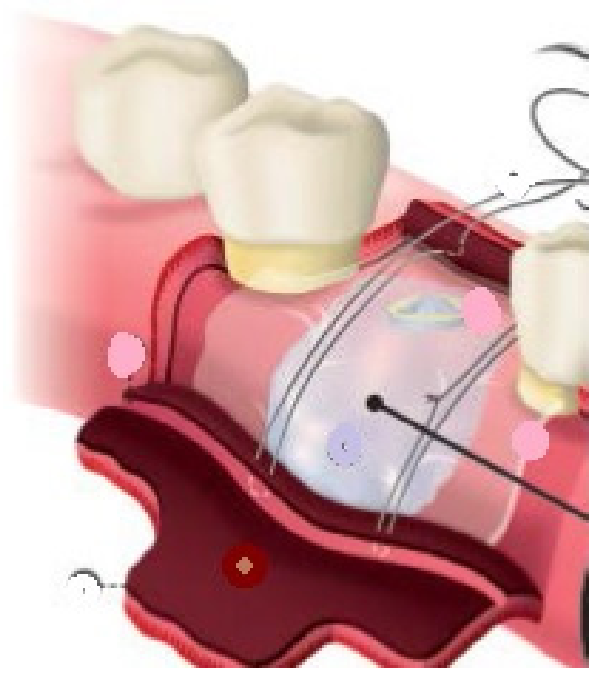

Figure 2. Membrane Fixation with Periosteal vertical mattress suture ${ }^{4}$

analgesics, and antiinflamatory drugs. One week later, the patients returned to remove periodontal dressing, and two weeks later they returned to remove the suture thread. These patients were advised to maintain oral hygiene. Control of oral hygiene and wound healing after surgery was done every 2 weeks for 4 weeks. Examination of $\mathrm{GI}, \mathrm{PI}$, $\mathrm{OHI}$ and scaling could then be performed. Clinical parameter examinations were performed in the first and third months after the treatment and recorded as post-treatment data. Method of this research approved by health research ethic committee Faculty of Dentistry UGM, with ethical clearance number 001236/KKEP/FKG-UGM/EC/2017.

\section{RESULTS}

This research was conducted at the periodontal clinic at Prof. Soedomo UGM Dental Hospital. Table 1 shows that the highest mean of PD was found in the group given membrane fixation using periosteal vertical mattress suture technique on day 0 (baseline), $5.60 \pm 0.52 \mathrm{~mm}$. The lowest mean of PD was found in the group given membrane fixation using periosteal vertical mattress suture technique on day $90,1.50 \pm 0.53 \mathrm{~mm}$.

The data in Table 2 show that the highest mean of PD reduction was found in the group of membrane fixation using periosteal vertical mattress suture on day 0 to day $904.10 \pm 0.98$ $\mathrm{mm}$. The lowest mean of PD reduction was found in the group of membrane fixation using simple sling suture on day 0 to day $30,1.30 \pm 0.48 \mathrm{~mm}$. The mean of PD reduction was greater in the group of membrane fixation with periosteal vertical mattress suture compared to the group of membrane fixation with simple sling suture on day 0 to day 30 , day 0 to day 90 , and day 30 to day 90 .

The $U$ Mann-Whitney test on PD reduction resulted in a significance of $p<0.05$, meaning that during the observation time, there was a statistically significant difference between the group of membrane fixation with periosteal vertical mattress suture and that with simple sling suture technique. During the observation time from day 30 to day 90 , there was no significant difference between the two groups.

Table 4 shows that the highest mean of RAL was found in the group of membrane fixation with periosteal vertical mattress suture technique on day 0 (baseline), $9.70 \pm 0.82 \mathrm{~mm}$. The lowest mean of RAL was found in the group of membrane fixation with simple sling suture technique on day 906.30 $\pm 0.67 \mathrm{~mm}$.

The data in Table 5 show that the highest mean of RAL reduction was found in the group of membrane fixation with periosteal vertical mattress suture from day 0 to day $903.40 \pm 0.84 \mathrm{~mm}$. The lowest mean of RAL reduction was found in the group of membrane fixation with simple sling suture from day 30 to day $901.10 \pm 0.32 \mathrm{~mm}$. 
Majalah Kedokteran Gigi Indonesia. August 2019; 5(2): 75 - 81 ISSN 2460-0164 (print)

ISSN 2442-2576 (online)

The $U$ Mann-Whitney test on PD reduction resulted in a significance of $p<0.05$, indicating that during the observation time there was statistically significant difference between the group of membrane fixation with periosteal vertical mattress suture and that with simple sling suture. During the period from day 30 to day 90 , there was no significant difference between the two groups.

Table 7 shows that the highest mean of alveolar bone height was found in the group of membrane fixation with simple sling suture technique on day 0 $9.23 \pm 2.18 \mathrm{~mm}$. The lowest mean of alveolar bone height was found in the group of membrane fixation with periosteal vertical mattress suture on day 90 , $3.29 \pm 0.72 \mathrm{~mm}$

The level of significance of the parametric paired t-test was $p<0.05$, indicating that there were significant differences in the alveolar bone height among the observation time in each group. However, the parametric Independent t-test on alveolar bone height reduction from day 0 to day 90 resulted in a significance of $p>0.05$, meaning that during the observation time, there was no statistically significant difference between the group of membrane fixation with periosteal vertical mattress suture and that with simple sling suture technique.

Table 1. Mean and standard deviation of PD according to observation time and treatment groups

\begin{tabular}{cccc}
\hline Time & $\mathrm{n}$ & Simple sling & Vertical mattress \\
\hline Day 0 & 10 & $5.50 \pm 0.53$ & $5.60 \pm 0.52$ \\
Day 30 & 10 & $4.20 \pm 0.42$ & $3.60 \pm 0.52$ \\
Day 90 & 10 & $2.20 \pm 0.42$ & $1.50 \pm 0.53$ \\
\hline
\end{tabular}

Table 2. Mean and standard deviation of PD reduction according to observation time and treatment groups

\begin{tabular}{cccc}
\hline Time & $\mathrm{n}$ & Simple sling & Vertical matress \\
\hline Day 0 to day 30 & 10 & $1.30 \pm 0.48$ & $2.00 \pm 0.67$ \\
Day 30 to day 90 & 10 & $2.00 \pm 0.00$ & $2.10 \pm 0.57$ \\
Day 0 to day 90 & 10 & $3.30 \pm 0.48$ & $4.10 \pm 0.98$ \\
\hline
\end{tabular}

Table 3. Results of $U$ Mann Whitney test on PD reduction according to observation time

\begin{tabular}{lcccccc}
\hline & VMS, & SS, & VMS, & SS, & VMS, & SS, \\
& $0-30$ & $0-30$ & $0-90$ & $0-90$ & $30-90$ & $30-90$ \\
\hline VMS, & - & & & & & \\
$0-30$ & & & & & & \\
SS, \\
$0-30$ & $0.019^{*}$ & - & & & & \\
VMS, & & & & & & \\
$0-90$ & $0.000^{*}$ & $0.000^{*}$ & - & & & \\
SS, & $0.001^{*}$ & $0.000^{*}$ & $0.032^{*}$ & - & & \\
$0-90$ & & & & & & \\
VMS, & 0.721 & $0.006^{*}$ & $0.000^{*}$ & $0.000^{*}$ & - & \\
$30-90$ & 0.72 & & & & \\
SS, & $0.001^{*}$ & $0.001^{*}$ & $0.000^{*}$ & $0.000^{*}$ & 0.543 & - \\
$30-90$ & 0.043 & & \\
\hline
\end{tabular}

Table 4. Mean and standard deviation of relative attachment loss (RAL) according to observation time and treatment groups

\begin{tabular}{lccc}
\hline \multicolumn{1}{c}{ Time } & $\mathrm{n}$ & Simple sling & Vertical matress \\
\hline Day 0 & 10 & $9.60 \pm 1.07$ & $9.70 \pm 0.82$ \\
Day 30 & 10 & $8.30 \pm 1.06$ & $7.70 \pm 0.67$ \\
Day 90 & 10 & $7.20 \pm 1.14$ & $6.30 \pm 0.67$
\end{tabular}

Table 5. Mean and standard deviation of relative attachment loss (RAL) reduction according to observation time and treatment groups

\begin{tabular}{lccc}
\hline \multicolumn{1}{c}{ Time } & $\mathrm{n}$ & Simple sling & Vertical matress \\
\hline Day 0 to day 30 & 10 & $1.30 \pm 0.48$ & $2.00 \pm 0.67$ \\
Day 30 to day 90 & 10 & $1.10 \pm 0.32$ & $1.40 \pm 0.52$ \\
Day 0 to day 90 & 10 & $2.40 \pm 0.52$ & $3.40 \pm 0.84$ \\
\hline
\end{tabular}

Table 6. Results of post hoc Mann Whitney test on relative attachment loss (RAL) reduction among treatment groups

\begin{tabular}{lcccccc}
\hline & VMS, & SS, & VMS, & SS, & VMS, & SS, \\
& $0-30$ & $0-30$ & $0-90$ & $0-90$ & $30-90$ & $30-90$ \\
\hline VMS & - & & & & & \\
$0-30$ & & & & & & \\
SS & $0.019^{*}$ & - & & & & \\
$0-30$ & & & & & & \\
VMS & $0.002^{*}$ & $0.000^{*}$ & - & & & \\
$0-90$ & & & & & & \\
SS & & $0.001^{*}$ & $0.007^{*}$ & - & & \\
$0-90$ & 0.165 & & & & & \\
VMS & $0.044^{*}$ & 0.648 & $0.000^{*}$ & $0.002^{*}$ & - & \\
$30-90$ & & & & & & \\
SS, & $0.002^{*}$ & 0.276 & $0.000^{*}$ & $0.000^{*}$ & 0.131 & - \\
$30-90$ & & & & & \\
\hline
\end{tabular}

Description: SS: simple sling suture; VMS: vertical mattress suture 
Table 7. Mean and standard deviation of alveolar bone height according to observation time and treatment groups

\begin{tabular}{cccc}
\hline Time & $\mathrm{n}$ & Simple sling & Vertical matress \\
\hline Day 0 & 10 & $9.23 \pm 2.18$ & $4.86 \pm 0.83$ \\
Day 90 & 10 & $7.89 \pm 1.83$ & $3.29 \pm 0.72$ \\
\hline
\end{tabular}

Table 8. Results of parametric paired t-test on alveolar bone height among observation time and treatment groups

\begin{tabular}{|c|c|c|c|c|}
\hline & $\begin{array}{c}\text { Bone height } \\
\text { month } 0\end{array}$ & $\begin{array}{c}\text { Bone height } \\
\text { month } 3\end{array}$ & $\begin{array}{c}\text { Significance } \\
\text { level }\end{array}$ \\
\hline & & Mean \pm SD & Mean \pm SD & $\mathrm{p}$ \\
\hline \multirow[t]{2}{*}{ Group } & $\begin{array}{l}\text { Vertical } \\
\text { Mattress } \\
\text { Suturing }\end{array}$ & $4.86 \pm .83$ & $3.29 \pm 0.72$ & 0.004 \\
\hline & $\begin{array}{l}\text { Simple Sling } \\
\text { Suture }\end{array}$ & $9.23 \pm 2.1$ & $7.89 \pm 1.83$ & 0.001 \\
\hline
\end{tabular}

Table 9. Results of parametric independent t-test on alveolar bone height reduction among treatment groups

\begin{tabular}{cc}
\hline Observation time & Significance level $(p)$ \\
\hline Day 0 to day 90 & 0.659 \\
\hline
\end{tabular}

\section{DISCUSSION}

The descriptive data of PD show that there was a downward trend of PD, in both groups of suture technique in every observation time, starting from day 0 (baseline) which decreases after day 30 and declines again after day 90 . According to the observation time in each group, there was a significant difference. This means that there was an improved clinical condition of patients in both treatment groups over time after treatment. The reason for PD reduction in both groups is that the use of bone graft material in the treatment of infrabony pockets can stimulate bone formation and osteoconducted periodontal regeneration, thus forming a scaffold for the formation and remodeling of bone, periodontal ligaments and cementum. ${ }^{10}$

Reduction of PD from day 0 to day 30 and from day 0 to day 90 resulted in a significant difference between the two treatment groups. The reduction in the group with periosteal vertical mattress suture technique was greater than that of the group with simple sling suture technique. This means that periosteal vertical mattress suture technique had strength in the form of great compressive strength because periosteal vertical mattress suture has 2 anchors attached to periosteum, while simple sling suture only has 1 anchor in coronal area, causing it to have less compressive strength. ${ }^{8}$

Periodontal depth reduction from day 30 to day 90 resulted in insignificant differences between the two treatment groups. This is because wound healing already entered the remodeling phase, where the new cells formed after inflammation and proliferation underwent maturation so they became slower. New cell regeneration increases rapidly in both inflammatory and proliferative phases then decreases in remodeling phase. ${ }^{11}$

The descriptive data of RAL showed a downward trend of RAL, both in the group of open flap debridement with periosteal vertical mattress suture technique and in the group of open flap debridement with simple sling suture at each observation time, starting from day 0 (baseline) which decreased after day 30 and declined again after day 90 . There was significant RAL reduction after open flap was performed with an addition of bone graft and membrane, starting from the beginning of the observation time. ${ }^{10} \mathrm{RAL}$ reduction in both treatment groups indicated the formation of new attachments to tooth root surfaces. Significant $\mathrm{RAL}$ reduction up to $\pm 2 \mathrm{~mm}$ occurred 3 months after open flap and DFDBA was performed. ${ }^{12}$

The results of RAL reduction from day 0 to day 30 and from day 0 to day 90 showed a significant difference between the two treatment groups. The reduction of the group given periosteal vertical mattress suture technique was greater than that of the group given simple sling suture technique, meaning that would healing process in the group with simple sling suture technique took longer than that in the group with periosteal vertical mattress suture technique. In fact, less stable fixation influences both wound healing and regeneration processes. ${ }^{8}$

Attachment level is generally, although not always, correlated to probing depth. This is because attachment level depends on the location of the base of pocket on the root surface, and the position of gingival margin towards cementoenamel junction or particular position. ${ }^{3}$

Based on the results of this study, some teeth underwent recession both in the group of membrane 
fixation with periosteal vertical mattress suture and in the group with simple sling suture technique, although RAL decreased. Gingival recession increased due to shrinkage which occurred because tissues with inflammation healed. An increase in gingival recession of $\pm 1.2 \mathrm{~mm}$ occurred after open flap with bone graft material was performed. ${ }^{13}$

The data showed that the alveolar bone height on day 90 was lower than that on day 0 (baseline) both in the group of membrane fixation with periosteal vertical mattress suture technique and in the group with simple sling suture technique. In fact, reduced alveolar bone height indicates bone repair over time. Alveolar bone regeneration can be seen from radiographic examination, where radiopaque image of alveolar bone can be seen. ${ }^{14}$

The comparison of alveolar bone height during the observation time at each treatment group showed significant results, meaning that the two groups had good bone regeneration. DFDBA has been proven to be effective in reducing pocket depth and improving clinical attachment as well as bone regeneration. In addition, DFDBA is osteoinductive so it is able to activate bone morphogenic protein which then transforms undifferentiated mesenchymal stem cells into osteoblasts. Membrane fixation in both groups is able to hold DFDBA longer in the bone defect area. ${ }^{3}$

The result of alveolar bone height reduction from day 0 to day 90 in the group with periosteal vertical mattress suture technique was greater than that in the group with simple sling suture technique, but there was no significant difference in alveolar bone damage between the two groups. This shows that membrane fixation with periosteal vertical mattress suture and simple sling suture underwent the same bone regeneration process. Regeneration of bone damage starts 1 month after transplantation. ${ }^{15}$ The mechanism of new bone formation after the bone defect area is given bone graft materials generally includes hemostasis, inflammation, proliferative, and remodeling phases. Bone remodeling phase is slow and affected by mechanical stress. ${ }^{11}$ The maturation of bone graft material in laminar bone requires varied healing time ranging from 3 to 6 months depending on several factors such as age, wound healing factor, size of bone damage in the grafting area. ${ }^{16}$

\section{CONCLUSION}

Based on the results of this study it can be concluded that: compared to membrane fixation with simple sling suture technique, membrane fixation in the treatment of infrabony pockets with periosteal vertical mattress suture technique is more effective in reducing probing depth and relative attachment loss, but there is no difference in increasing alveolar bone height. The treatment of infrabony pockets with membrane fixation yields satisfactory results but further research is still needed to examine flap suturing technique after membrane fixation to reduce the risk of gingival recession after treatment. In addition, research on bone damage reduction with a longer observation time is needed to see alveolar bone stabilization.

\section{REFERENCES}

1. Fedi PF, Vernino AR, Gray JL. Silabus Periodonti ed.4 (terj.). Jakarta: Penerbit EGC; 2004. 167-172

2. Manson JD, Eley BM. Buku Ajar Periodonti ed.2 (terj.). Jakarta: Hipokrates; 2012. 127

3. Newman MG, Takei HH, Carranza FA, Klokkevold PR. Carranza's Clinical Periodontology, $\quad 11^{\text {th }}$ ed. Philadelphia: W.B.Saunders Co; 2012.127-139.

4. Urban IA, Lozada JL, Wessing B, SuarezLopez del Almo F, Wang HL. Vertical bone grafting and periosteal vertical mattress suture for the fixation of resorbable membranes and stabilization of particulate grafts in horizontal guided bone regeneration to achieve more predictable results. Int J Periodontics Restorative Dent. 2016; 36(2): 153-159. doi: 10.11607/prd.2627.

5. Bartold PM, Gronthos S, Ivanovski S, Fisher A, Hutmacher DW. Tissue engineered periodontal products. J Periodontal Res. 2016; 51(1): 1-15. doi: 10.1111/jre.12275

6. Wang J, Wang L, Zhou Z, Lai H, Xu P, Liao $\mathrm{L}$, Wei J. Biodegradable polymer membranes 
applied in guided bone/tissue regeneration: a review. Polymers (Basel). 2016; 8(4): 1-5. doi: 10.3390/polym8040115

7. Nagappa R, Elzer ASM, Younis SFB, Doddagoudar M. Surgical procedure for guided bone regeneration using resorbable membrane barrier for ridge augmentation in successful implant placement. Journal of Indian Academy of Dental Specialist Researchers. 2015; 2(2): 73-74. doi: 10.4103/2229-3019.177931

8. Siervo S, Lorenzini L. Suturing techniques in oral surgery. Quintessenza Edizioni S.r.l. Milano; 2008.170-173, 222-223.

9. Sato N. Periodontal Surgery Clinical Atlas. Illinois: Quintessence Publishing; 2000. 393.

10. Agarwal A, Gupta ND. Combination of bone allograft, barrier membrane and doxycycline in the treatment of infrabony periodontal defects: A comparative trial The Saudi Dental Journal. 2015; 27(3): 155-160.

11. Lindhe J, Lang NP, Karing. Clinical Periodontology and Implant Dentistry $5^{\text {th }}$. United Kingdom: Blackwell Munksgaard; 2008. 57-59.
12. Goti R, Bansal M, Kaushik M. A Comparative evaluation of freezee dried bone allograft, a clinical and radiographic study. J of Indian Soc Periodontol. 2015; 19(4): 411-415. doi: 10.4103/0972-124X.154169.

13. Schulean A, Nikolidakasis D, Nikou G. Biomaterials for promoting periodontal regeneration in in human intrabony defects: a systematic review. Periodontol. 2000. 2015; 68(1): 182-216. doi: 10.1111/prd.12086

14. Eickholz P, Krigar DM, Rawlison. Stability of clinical and radiographic results after GTR in infrabony defects. J Periodontol. 2007; 78(1): 37-46. doi: 10.1902/jop.2007.060097

15. Groeneveld EH, Burger EH. Bone morphogenetic proteins in human bone regeneration. Eur J Endocrinol. 2000; 142(1): 9-21. doi: 10.1530/eje.0.1420009

16. Hallman M, lundgren S, Seneby L. Histologic analysis of clinical biopsies taken 6 months and 3 years after maxillary sinus floor augmentation with $80 \%$ bovine hydroxyapatite and $20 \%$ autogenous bone mixed with fibrin glue. Clin Implant Dent Relat Res. 2001; 3(2): 87-96. doi: 10.1111/j.1708-8208.2001.tb00236.x 